\title{
Performance Evaluation of a New Type of Polymer Profile Control Agent
}

\author{
Qingwang Liu, Zhe Zhang, Zhenzhong Fan, Jigang Wang
}

EOR Key Laboratory of the Ministry of Education, Northeast Petroleum University, Daqing City, China Email: LIUQINGWANG@163.com, zhangzhe715@qq.com, fanzhenzhong@163.com, wangjigang9999@163.com

Received 25 March 2015; accepted 30 April 2015; published 5 May 2015

Copyright (C) 2015 by authors and Scientific Research Publishing Inc.

This work is licensed under the Creative Commons Attribution International License (CC BY). http://creativecommons.org/licenses/by/4.0/

(c) $\underset{\mathrm{EY}}{(1)}$ Open Access

\begin{abstract}
The low-permeability oil and gas resources of our country are quite common and abundant. Their reserve has accounted for one-fifth of total oil reserves of our country, and their yield has constituted the important part of national petroleum annual yield, but its development is very difficult. Polymer gel technology is a technical method of improving sweep efficiency in recent years which substantially increases the viscosity of the polymer solution by adding a crosslinking agent to the polymer produced by intramolecular or intermolecular crosslinking.
\end{abstract}

\section{Keywords}

Low-Permeability, Polymer Gel, Profile Control Agent

\section{Preferred Formulations of Profile Control Agent}

Profile control agent is made up of main agent, crosslinking agents and additives. The main agent is HPAM; the main raw material of crosslinking agent is chromium chloride; and additive is mainly thiourea [1].

\subsection{Determination of Polymer Concentration}

The results show that the solution initial viscosity and gel viscosity heighten with the increase of polymer concentration. Considering the gel viscosity and actual injection ability, we determine that the suitable polymer concentration is 800 - $1200 \mathrm{mg} / \mathrm{L}$ (Figure 1 and Figure 2).

\subsection{Development of Crosslinking Agent}

The main raw material of synthesis crosslinking agent is chromium chloride. The main component of crosslinking agent which reacts with the partially hydrolyzed polyacrylamide is chromium ions. The results show that the 


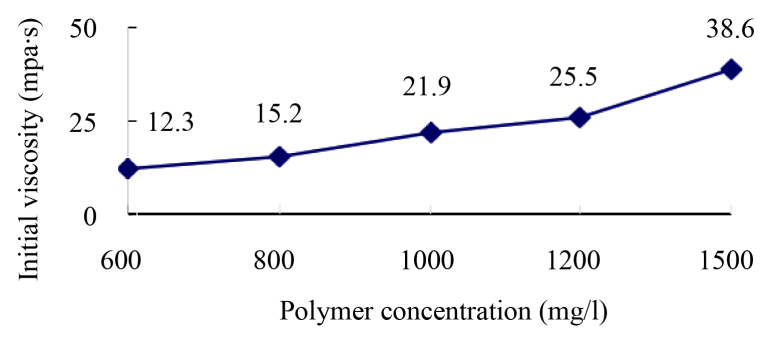

Figure 1. The curve of initial viscosity at different polymer concentration.

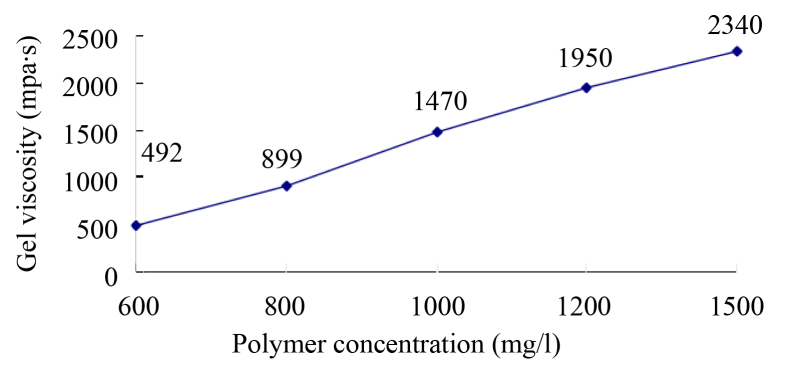

Figure 2. The curve of gel viscosity at different polymer concentration.

suitable $\mathrm{pH}$ value of gel formation ranges 6.5 from 8.5. The optimal composition of the crosslinking agent is shown in the Table 1.

\subsection{Determination of the Ratio of Crosslinking}

When the polymer and the crosslinking agent are confirmed, the ratio of polymer concentration, polymer/crosslinker ratio of the polymer solution is the key factor that affects the gelling properties of the polymer solution. By experiment we found that gel viscosity increased with an increase in crosslinking ratio. Considering gel viscosity and economic efficiency, we determine the suitable crosslinking ratio is 15:1 (Figure 3).

\subsection{The Determination of Additive Concentration}

By experiment we found that $\mathrm{NaCl}$ and $\mathrm{NaHCO}_{3}$ could adjust the speed of the crosslinking system [2], the higher the concentration, the faster the crosslinking reaction. By experiment we found that adding $600-800 \mathrm{mg} / \mathrm{L}$ $\mathrm{NaCl}$ and $500-750 \mathrm{mg} / \mathrm{L} \mathrm{NaHCO}_{3}$ was the most suitable and the optimal concentration was $1000 \mathrm{mg} / \mathrm{L}$ with thiourea as a stabilizer for the gel formulation (Figure 4 and Figure 5).

\subsection{The Determination of Profile Control Agent Formulation}

Considering the reservoir permeability, reservoir temperature, injection pressure and other factors, we determine the suitable profile control system formulation as shown in Table 2.

\section{Performance Evaluation of Profile Control Agent}

\subsection{The Compatibility with Injected Water}

By experiment we found that polymer prepared by injecting water has a good crosslinking properties with crosslinker mixed solution, and the crosslinking system also has good compatibility with injected water (Figure 6).

\subsection{Rheology}

We determined the static flow curve of polymer solution at a concentration of $1000 \mathrm{ppm}$ and profile liquid after the formation of the gel, then we found the rheological type of polymer solution and the gel is same, which is 
Table 1. The composition of the crosslinking agent.

\begin{tabular}{cccc}
\hline Name & Chromium chloride & Lactate & $\mathrm{NaOH}$ \\
\hline Content $(\%)$ & 2.22 & 2.65 & 1.96 \\
\hline
\end{tabular}

Table 2. The formulations of profile.

\begin{tabular}{cccccc}
\hline Composition & HPAM $(\mathrm{mg} / \mathrm{L})$ & Thiourea $(\mathrm{mg} / \mathrm{L})$ & $\mathrm{NaCl}(\mathrm{mg} / \mathrm{L})$ & $\mathrm{NaOH}(\mathrm{mg} / \mathrm{L})$ & Crosslinking ratio \\
\hline Slug 1 & 800 & 1000 & 600 & 500 & $15: 1$ \\
Slug 2 & 1000 & 1000 & 800 & 750 & $15: 1$ \\
Slug 3 & 1200 & 1000 & 800 & 650 & $15: 1$ \\
\hline
\end{tabular}

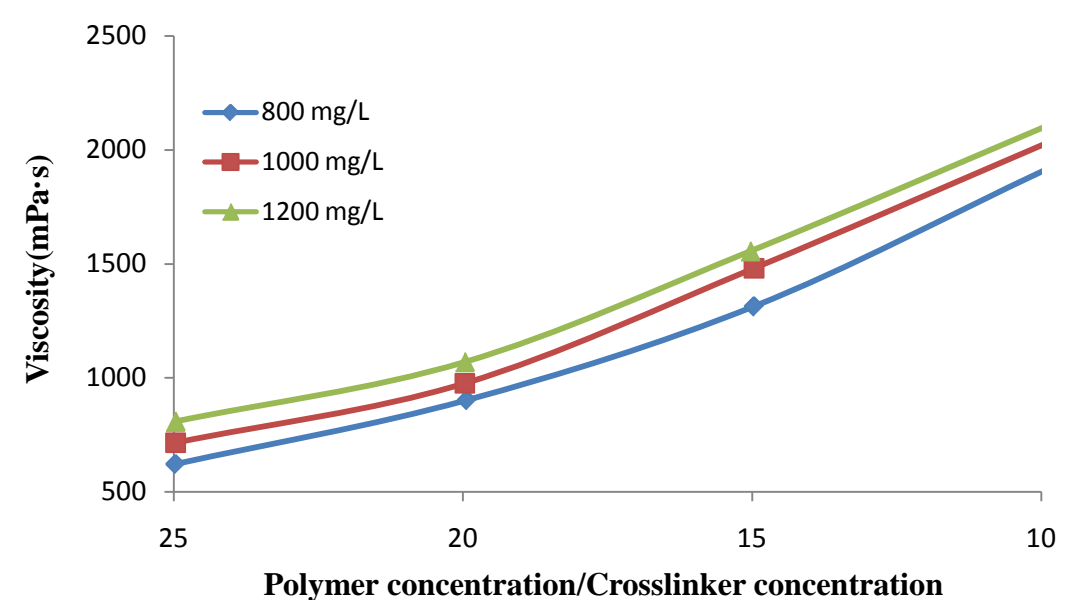

Figure 3. The curve of different crosslinking ratio and gel viscosity.

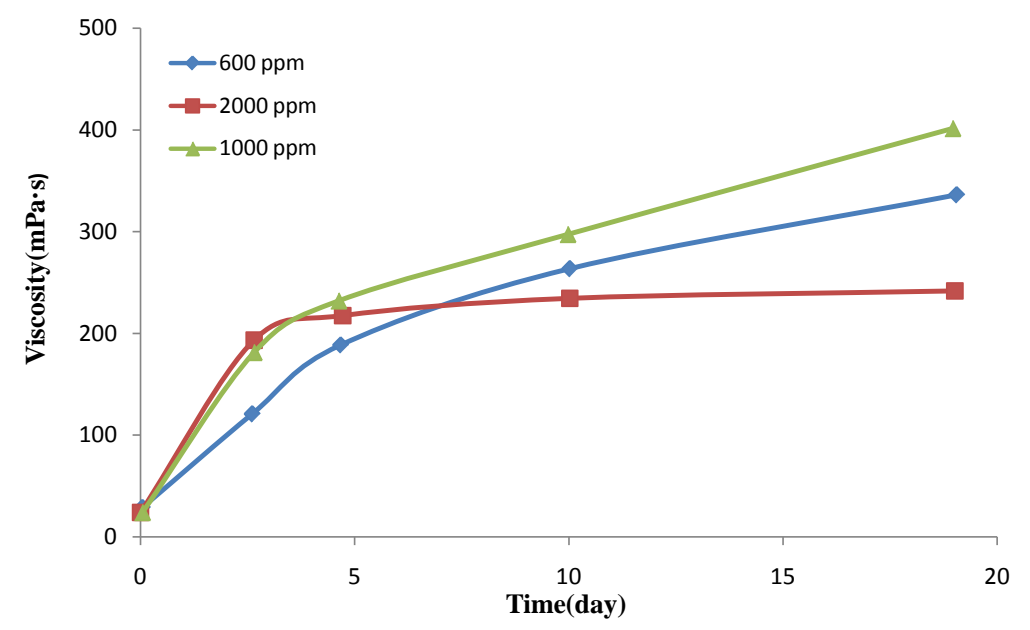

Figure 4. The effect of $\mathrm{NaCl}$ concentration on the gelling time.

similar to plastic non-Newtonian fluid having a yield stress [3]. The gel has large yield stress and high viscosity, which shows that gel has better control of mobility. The shear stability of profile control agent at $70^{\circ} \mathrm{C}$ is shown as Table 3.

Experimental results show that the mechanical shear has greater impact on the gel strength, shear viscosity decreased by $50 \%$ in the shear conditions, but the viscosity under the shear conditions still meets the fields application requirements. 


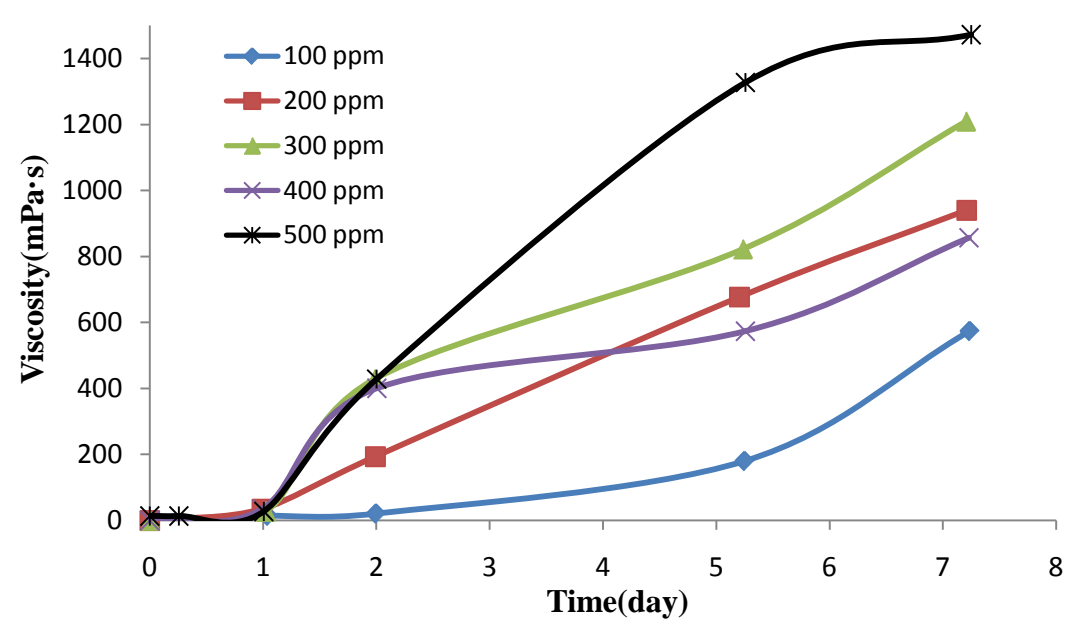

Figure 5. The effect of $\mathrm{NaHCO}_{3}$ concentration on the gelling time.

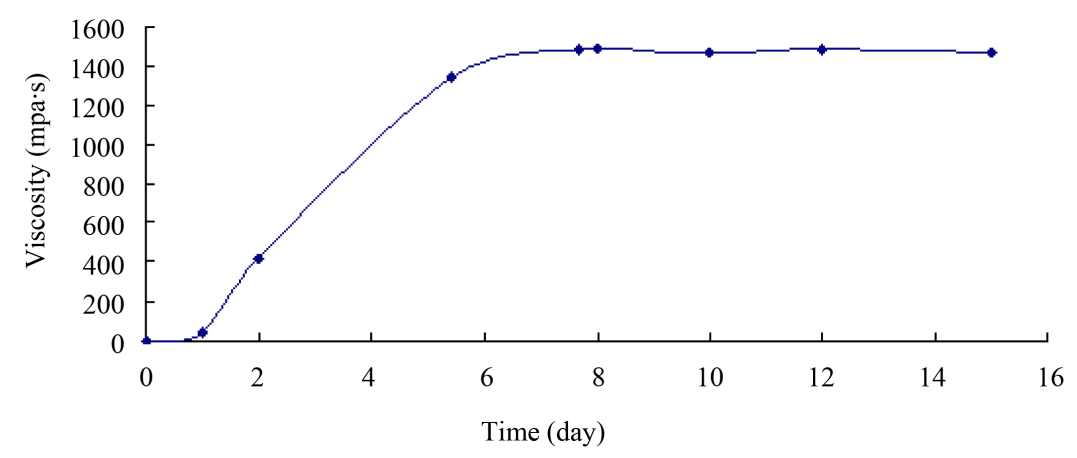

Figure 6. The gel curve of profile control agent prepared with water injection.

Table 3. Shear stability.

\begin{tabular}{ccccc}
\hline $\begin{array}{c}\text { The concentration of profile } \\
\text { control agent (\%) }\end{array}$ & $\begin{array}{c}\text { No shear } \\
(\mathrm{mPa} \cdot \mathrm{s})\end{array}$ & $\begin{array}{c}\text { Gel viscosity } \\
(\mathrm{mPa} \cdot \mathrm{s})\end{array}$ & $\begin{array}{c}\text { Initial viscosity } \\
(\mathrm{mPa} \cdot \mathrm{s})\end{array}$ & $\begin{array}{c}\text { Gel viscosity } \\
(\mathrm{mPa} \cdot \mathrm{s})\end{array}$ \\
\hline 0.5 & 286 & 116,300 & 127 & 59,765 \\
0.6 & 398 & 155,609 & 156 & 63,553 \\
\hline
\end{tabular}

Remark: shear speed: 4000 r/min, shear time: 5 min.

\subsection{The Effect of Temperature to the Gel Time of the Mixed Solution of Polymer and Crosslinker}

For the study of the effect of temperature to the gel time of the mixed solution of polymer and crosslinker, we placed the mixed solution of polymer and crosslinker in $30^{\circ} \mathrm{C}, 45^{\circ} \mathrm{C}, 55^{\circ} \mathrm{C}, 65^{\circ} \mathrm{C}, 75^{\circ} \mathrm{C}$ environment respectively and measured the viscosity of the solution at different times [4]. The result is shown as Figure 7.

From the figure we found that temperature has great impact on the gel time, the higher the temperature, the shorter the gel time, so the gel time in cryogenic reservoir is much longer than in the mid or high-temperature reservoir for the crosslinking system.

\section{Conclusions}

1) Through laboratory experiments, we select a suitable formula of profile control agent. Polymer concentration is $800-1200 \mathrm{mg} / \mathrm{L}$. Crosslinking ratio is $15: 1$. Using $\mathrm{NaHCO}_{3}$ and $\mathrm{NaCl}$ to control the gelation time of crosslinking system, their concentrations are 500 - $750 \mathrm{mg} / \mathrm{L}$ and $600-800 \mathrm{mg} / \mathrm{L}$, respectively. Thiourea is the 


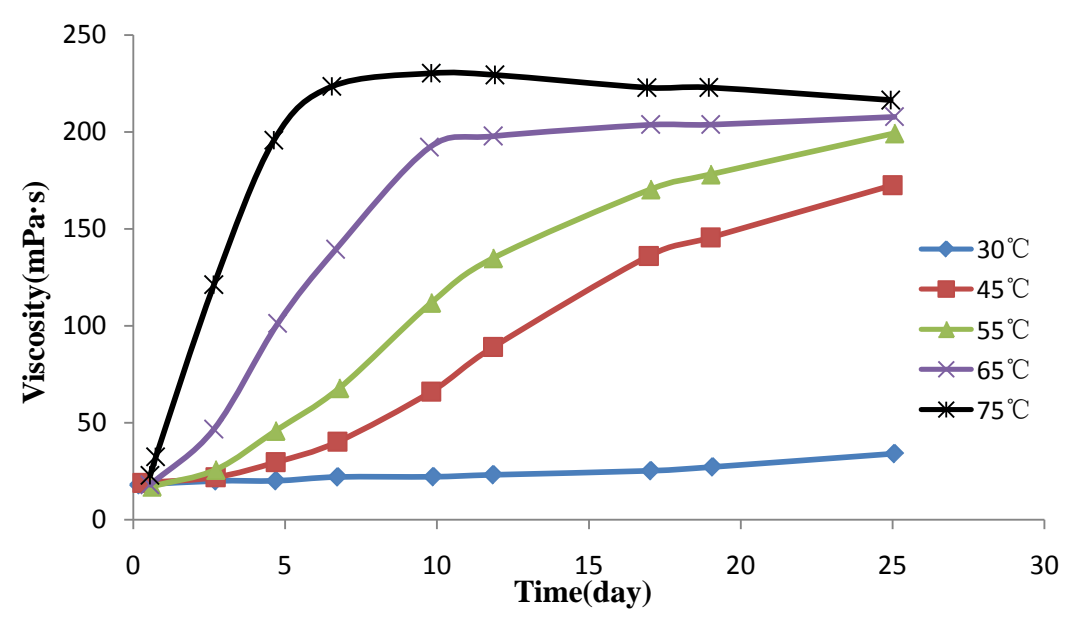

Figure 7. The effect of temperature on the gelling time.

stabilizing agent of gel in formula, whose concentration is $1000 \mathrm{mg} / \mathrm{L}$.

2) The crosslinking system formed by the formula has good compatibility and strong rheology with formation water and injected water, and temperature has larger effect on profile control agent.

\section{References}

[1] Small, G.P. (1986) Steam-Injection Profile Control Using Limited-Entry Perforations. Society of Petroleum Engineers, 1, 388-394. http://dx.doi.org/10.2118/13607-PA

[2] Li, M.W., Liu, H.F. and Wang, X.L. (2006) Key Techniques of Automatic Gauge Control and Profile Control for Aluminium Strip and Foil. Transactions of Nonferrous Metals Society of China, 32, 121-126.

[3] Chang-Il, S.O.N. (2012) Diffusion Tensor Interpolation Profile Control Using Non-Uniform Motion on a Riemannian Geodesic. Journal of Zhejiang University Science C (Computers \& Electronics), 94, 64-68.

[4] Liu, H.Q., Zhang, H.L., Wang, S.L., Wang, H. and Bao, S.C. (2006) Research on Mechanisms of Steam Breakthrough and Profile Control Design for Steam Soaking Well. Petroleum Science, 3, 82-85. 